\title{
VIOLÊNCIA FÍSICA NAS ESCOLAS MUNICIPAIS DE FEIRA DE SANTANA-BA E ESTRATÉGIAS DE CONSTRUÇÃO DA PAZ
}

\author{
Renata Sampaio Santana $^{1}$; Aisiane Cedraz Morais ${ }^{2}$; \\ 1. Bolsista PROBIC/UEFS, Graduanda em Enfermagem, Universidade Estadual de Feira de Santana, e-mail: \\ renatasantanass@hotmail.com \\ 2. Orientadora, Departamento de Saúde, Universidade Estadual de Feira de Santana, e-mail: aisicedraz@hotmail.com
}

PALAVRAS-CHAVE: Violência; Saúde Escolar; Estratégias.

\section{INTRODUÇÃO}

Violência, agressão, bullying, tortura, repressão, chantagem, entre outros, são termos utilizados quando se aborda o tema violência no cotidiano, inclusive na escola. A violência é um problema de saúde pública importante e crescente no mundo, com sérias consequências individuais e sociais, particularmente para os jovens, que aparecem nas estatísticas como os que mais morrem e os que mais matam (LOPES NETO, 2005).

Esta merece atenção especial quando atinge o espaço escolar, que é um local de formação social dos alunos, de fortalecimento da identidade e de construção de cidadania (CARDIA, 2006). Estudos detectaram ser a escola o terceiro local de maior ocorrência de casos de violência praticados contra crianças e adolescentes no município de Feira de Santana, aparecendo nos primeiros lugares, o domicílio e a via pública (SANTANA, 2006).

Assim, partimos do questionamento de como se configura a violência física nas escolas públicas municipais de Feira de Santana-BA, definindo como objetivo geral: compreender a violência física nas escolas públicas municipais de Feira de Santana-BA, na perspectiva de sistematização de estratégias para a construção de territórios de paz. E como objetivos específicos: identificar as faixas etárias e sexo mais vulneráveis para a vitimização da violência física; descrever as características dos agressores; identificar fatores associados com a prática da violência física nas escolas e construir propostas de redução da violência e construção da paz juntamente com a escola, a comunidade e o poder público.

\section{PERCURSO METODOLÓGICO}

Trata-se de uma pesquisa mista (qualitativa e quantitativa), realizada a partir de Banco de dados coletados durante a pesquisa "Diagnóstico da violência e estratégias de construção da paz nas escolas municipais de Feira de Santana-BA". Trata-se também de uma pesquisaação, que pressupõe interação, imprescindível, entre os envolvidos na situação de pesquisa.

Este estudo foi desenvolvido na cidade de Feira de Santana-BA, onde selecionamos aleatoriamente três escolas públicas municipais dentre as existentes no banco de dados para análise, totalizando 59 (81\%) estudantes e 13 (19\%) funcionários. Utilizou-se como técnicas de investigação a entrevista semiestruturada com aplicação de questionário autoaplicável.

A partir dos dados coletados tivemos o mapeamento da realidade em termos quantitativos, expressos em gráficos, enquanto a análise qualitativa foi operacionalizada em três etapas: Pré-análise, exploração do material e tratamento dos resultados obtidos e interpretação.

A realização desta investigação foi pautada em todos os preceitos éticos que envolvem Seres Humanos, em todas as fases da pesquisa. O projeto foi avaliado pelo CEP/UEFS, que emitiu paracer de aprovação com Protocolo n¹52/2010, CAE 0150.0.059.000-10.

Dada à diversidade de sujeitos que compuseram o universo deste estudo, foram elaborados três Termos de Consentimento distintos, abranagendo todos os componentes da pesquisa. Para preservar a confidencialidade dos entrevistados, foram utilizados como referência os códigos E1... E59 para os estudantes e F1... F13 para funcionários e professores. 


\section{RESULTADOS E DISCUSSÃO}

A faixa etária dos entrevistados possuiu variação de 7 a 47 anos de idade, sendo que foi predominante a faixa etária de 7-10 anos de idade (50\%). Sendo que destes entrevistados, houve uma maior prevalência do sexo feminino $(60,7 \%)$.

Entretanto, no que diz respeito aos agressores, a predominância foi do sexo masculino $(61,5 \%)$, corroborando com estudos que citam o gênero como o que apresenta mais condutas de risco, consequentemente, se expondo a mais situações de violência (COELHO et al, 2017). Bem como a faixa etária $10-14$ anos de idade $(73,5 \%)$ como os predominantes agressores.

Do quantitativo de pessoas que sofreram algum tipo de violência no nosso estudo $(69,4 \%), 44,1 \%$ deles referem ter sofrido violência física, 29,4\% violência psicológica e $26,5 \%$ foram submetidos aos dois tipos de violência, como está detalhado no gráfico seguinte.

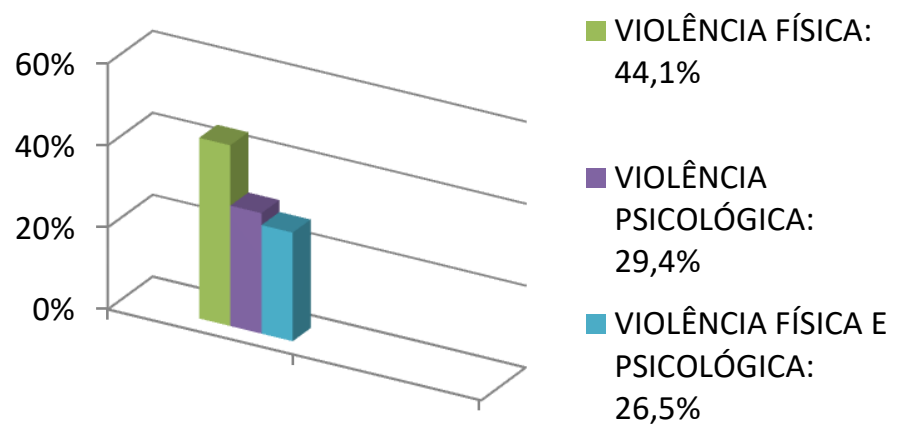

GRÁFICO 01. TIPOS DE VIOLÊNCIA, ESCOLAS PÚBLICAS MUNICIPAIS DE FEIRA DE SANTANA, BA, 2017. FONTE: Banco de Dados do PROVESC, 2012-2014.

Andrade e colaboradores (2012) asseguram que a violência física é o tipo de violência menos frequente no ambiente escolar, trazendo a violência psicológica em primeiro lugar nessas situações. Em contrapartida, o levantamento percentual realizado nesta pesquisa contradiz esta referência.

Quanto à atitude tomada pela vítima na situação de violência, a maioria delas não fizeram nada a respeito $(43,2 \%)$, sendo que a maioria das situações de violência $(62,9 \%)$ ocorreu no ambiente escolar.

O sexo masculino é o que agride mais, ainda que o sexo feminino esteja em maior número dentre os participantes do estudo. Chama atenção o número de vítimas que não fizeram nada diante a situação de violência, evidenciando a falta de apoio a essas pessoas, seja pela escola, família ou equipe de saúde.

Além da análise quantitativa, foi possível analisar o que os estudantes e funcionários compreendem sobre o que é a violência e as intervenções associadas a esse contexto. Neste sentido, foi possível estabelecer as categorias de análise temáticas, a constar: 1. Compreensões sobre violência; 2. Fatores para ocorrência da Violência; e 3. Intervenções e Estratégias de Construção da Paz.

Quanto às compreensões sobre violência, os relatos evidenciam o sentimento de tristeza e/ou repúdio dos alunos, entre os quais destaco os relatos abaixo:

"É um absurdo e uma vergonha". (E37)

"Muito triste porque a escola é para aprender e não para ser violento". (E44)

Estas falas evidenciam a necessidade de atenção a este problema, nos motivando a investigar as compreensões destes componentes no cenário escolar, os fatores que levam estas pessoas a cometerem atos violentos e, consequentemente, pensarmos em estratégias de melhorias, no sentido de construção da paz.

Os adolescentes referem à família como peça fundamental para dar suporte e apoio aos seus membros, bem como podem ser fatores de risco se estão ausentes ou em situações de conflito (Cortez, Carvalho, Lamounier, 2013). 
Araújo e colabores (2012) referem que 57,8\% dos alunos não se sentem seguros na escola, nítido na fala de um aluno ao ser questionado sobre o que acha da violência escolar:

"Ruim porque não temos segurança". (E15)

No estudo de Araújo e colaboradores (2012) com os adolescentes, as palavras que mais apareceram foram: roubar, matar, machucar, brigar, dar murros, xingar e falar palavrão, palavras estas encontradas nas falas que dispusemos posteriormente, referentes ao questionamento sobre às compreensões acerca da violência:

"Bater, maltratar as pessoas" (E24)

"É uma pessoa que bate nas outras pessoas" (E53)

Observa-se a relação que os entrevistados fazem da violência para com a agressão física, justificando a prevalência da violência do tipo física no nosso estudo. Além destas, duas frases chamam atenção:

"Assassinatos, estupros e pancadaria" (E13)

"Matar, roubar e chingar" (E23)

Essas associações sugerem como a violência está "naturalizada" no cotidiano desses adolescentes, através de atos mais agressivos com impacto na vida do outro, visto quando eles associam a violência a homicídios e violência sexual. Em outras falas, como:

"É um modo de mostrar que manda mais quem é o mais forte". (E7)

"É uma pessoa que se acha valentão" (E29)

Podemos observar a relação de hierarquia pela superioridade física, vista no estudo de Becker e Kassouf (2016), onde o comportamento de agressão daquele jovem o beneficia com o status da imposição da superioridade, por praticar a violência.

Outra fala que chamou atenção foi de uma funcionária da escola ao referir que:

“A violência escolar já começa pelos próprios governantes, quando a escola e seu estado físico é péssimo, a baixa remuneração dos profissionais de educação, alunos com problema familiar. O desemprego e as drogas". (F1)

Este relato nos leva a compreender que a violência é multifatorial, como mencionado por Debarbieux e Blaya (2002) que apontam os fatores psicológicos, familiares e socioeconômicos como variáveis determinantes da violência escolar.

Quanto aos fatores para ocorrência da violência, encontramos as seguintes falas:

"Porque muitas vezes as crianças não têm amor e carinho necessário em casa com a família". (F11)

"Acho que não seja só na escola porque eles já vêm de casa com o intuito de provocar o mal". (E16)

"Por falta de humanidade e de amor ao próximo". (E51)

Debarbieux e Blaya (2002) caracterizam esses fatores em quatro subdivisões: Fatores psicológicos, familiares, fatores relativos a colegas, condições econômicas e vizinhança e por fim, fatores circunstanciais. Todas essas subdivisões foram encontradas em falas dos sujeitos da pesquisa, como demonstrado anteriormente.

No que diz respeito às intervenções e estratégias de construção da paz, houve o questionamento sobre o que se deve fazer acerca da violência na escola, onde alguns responderam pensando especificamente na agressão física:

"Deve se separar a briga". (E55)

"Providenciar policiais para ficar na portaria revistando e no pátio na hora do intervalo". (E39)

Estes pensaram na prevenção da violência cogitando um maior policiamento, forma de prevenção que coincide com a apontada pelos adolescentes nos estudos de Njaine e Minayo (2003). Métodos como acolher e dialogar com o jovem; melhorar o ambiente escolar; trabalhar os problemas de forma alternativa e melhorar os laços de convivência são propostos por Njaine e Minayo (2003), e encontrados nas falas: 
"Dar conselhos aos nossos colegas e quando ver alguns colegas fazendo alguma coisa errada, falar pra professora". (E26)

"Construir projetos que possam valorizar o amor, amizade, relações interpessoais, diferenças culturais, sociais e econômicas". (F5)

Njaine e Minayo (2003) referem que os educadores se sentem impotentes, não se sentindo preparados para intervir nas situações de violência. Esta impotência foi percebida na fala de um aluno quando questionado sobre o que ele poderia fazer nestas situações:

"Nada porque eu sou muito pequeno e não posso fazer nada na escola". (E18)

\section{CONCLUSÃO}

A maioria das pessoas inseridas no ambiente escolar já sofreu algum tipo de violência, onde a violência física está mais evidenciada, principalmente no que diz respeito aos adolescentes, já que foi percebido, numa análise qualitativa, que professores e funcionários sofrem mais com a violência psicológica, onde eles referem episódios de bullying e diversas formas de agressões verbais.

As medidas a serem tomadas em situações de violência devem estar esclarecidas, para que as vítimas se sintam menos vulneráveis. Nas intervenções realizadas no ambiente escolar, foi possível, de forma subjetiva, observar situações de violência, bem como o comportamento receoso de quem é vítima e o aspecto de superioridade de quem é agressor. Algumas situações vivenciadas neste contexto puderam reafirmar o que a nossa pesquisa demonstrou nos resultados. A escola, a família e a equipe de saúde devem estar atentas a estes episódios, adotando medidas preventivas no intuito de promover estratégias para construção da paz.

\section{REFERÊNCIAS}

ANDRADE, S. e cols., Relação entre violência física, consumo de álcool e outras drogas e bullying entre adolescentes escolares brasileiros, Cadernos de Saúde Pública, Rio de Janeiro, v. 28, n. 9, pp. 1725-1736, SEP, 2012.

ARAUJO, L. e cols . Universo consensual de adolescentes acerca da violência escolar. PsicoUSF, Bragança Paulista, v. 17, n. 2, p. 243-251, maio/agosto 2012.

BECKER, K; KASSOUF, A. Violência nas escolas públicas brasileiras: uma análise da relação entre o comportamento agressivo dos alunos e o ambiente escolar. Nova econ., Belo Horizonte, v. 26, n. 2, p. 653-677, 2016.

CARDIA, Nancy. Introdução. IN: RUOTTI, C.; ALVES, R.; CUBAS, V. de O. Violência na escola: um guia para professores. São Paulo: Andhep - Imprensa Oficial do Estado de São

Paulo, 2006.

COELHO, M., RAPOSO, J., COSTA, A., VALENçA, P., COLARES, V., DA FRANCA, C.. Fatores de risco para a saúde de adolescentes escolares: diferenças entre os sexos. Revista de enfermagem UFPE on line, Recife (PE), 11, abr. 2017.

CORTEZ, D., CARVALHO, A., LAMOUNIER, J.. Representação social de violência para adolescentes em medida socioeducativa de internação. Revista de enfermagem UFPE on line, Recife (PE), 2013.

DEBARBIEUX, E.; BLAYA, C. Violência nas escolas e políticas públicas. Brasília: UNESCO, 2002. 268p.

LOPES NETO, Aramis A. Bullying: comportamento agressivo entre estudantes. J. Pediatr. (Rio J.) [online], vo.81, 2005.

NJAINE, K.; MINAYO, M. C. S. Violência na escola: identificando pistas para a prevenção, Interface - Comunic, Saúde, Educ, v.7, n.13, p.119-34, 2003.

SANTANA, Judith Sena da S. Violência física contra crianças e adolescentes em Feira de Santana-Ba. Feira de Santana: Núcleo Interdisciplinar de Estudos sobre Violência e Saúde (NIEVS)/(UEFS), 2006. 